KREATIF

Jurnal Ilmiah

Prodi Manajemen Universitas Pamulang
ISSN: 2339-0689 (Print), ISSN 2406-8616 (Online)

Volume 7, No 1 Juni 2019, (Halaman 93-102)

Tersedia online di http://openjournal.unpam.ac.id/index.php/kreatif

\title{
PENGARUH KEPEMIMPINAN DAN DISIPLIN KERJA TERHADAP MOTIVASI SERTA DAMPAKNYA TERHADAP KINER JA KARYAWAN STUDI PADA PT ATLASRESOURCES TBKJAKARTA SELATAN
}

\author{
Dede Andi \\ Program Studi Manajemen \\ Universitas Pamulang \\ dosen02463@unpam.ac.id
}

\begin{abstract}
ABSTRAK
Penelitian ini dibuat dengan tujuan agar mendapat informasi tentang pengaruh kepemimpinan dan pengaruh disiplini kerja terhadap motivasi kerja karyawan yang berdampak kepada kinerja karyawan studi pada PT Atlas Resources Tbk. Jakarta Selatan.

Metode penelitian yang digunakan adalah dengan metode asosiatif klausal, untuk pengujian dan pengukuran pengaruh masing-masing variabel dengan menggunakan program statistik yaitu Statistical Package for Social Science (SPSS) versi 24. subjek yang digunakan yaitu seluruh karyawan PT Atlas Resources Tbk Jakarta Selatan sebanyak 125 orang.

Hasil penelitian pada PT Atlas Resources Tbk Jakarta Selatan sebagai berikut : (1) Terdapat pengaruh positif dan signifikan antara variabel kepemimpinan terhadap motivasi dengan $t_{\text {hitung }} 21,665>t_{\text {tabel }} 1,979$ koefisien determinasi sebesar 79,2\%. (2) Terdapat pengaruh positif dan signifikan antara variabel disiplin kerja terhadap motivasih denga nilai $\mathrm{T}_{\text {hitung }} 23,948>\mathrm{t}_{\mathrm{tabel}} 1,979$ koefisien determinasi sebesar 81,8\%. (3)Terdapat pengaruh positif dan signifikan antra variabel kepemimpinan dan disiplin kerja terhadap motivasi karyawan hasi $F_{\text {hitung }} 326,518>F_{\text {tabel }}$ 3,07, koefisien determinasi sebesar $84,3 \%$. (4)Terdapat pengaruh positif dan signifikan antara variabel kepemimpinan terhadap kinerja dengan thitung $21,368>t_{\text {tabelt }} 1,979$, koefisien determinasi sebesar 78,8\%. (5) Terdapat pengaruh positif dan signifika antara variabel disiplin kerja terhadap kinerja dengan nilai thitung $29,408>t_{\text {tabel }} 1,979$, koefisien determinasi sebesar $87,5 \%$. (6)Terdapat pengaruh positif dan signifikan antara variabel motivasi kerja terhadap kinerja dengan nilai thitungn $22,927>t_{\text {tabel }} 1,979$, koefisien determinasi sebesar $81 \%$. Dengan demikian maka dari tiap-tiap variabel dapat mpengaruhi secaran signifikan terhadap motivasi yang berdampak positif dalam meningkatkan kinerja karyawan pada PT Atlas Resources Tbk Jakarta Selatan.
\end{abstract}

Kata Kunci : Kepemimpinan, Disiplin Kerja, Motivasi, dan Kinerja.

\section{ABSTRACT}

This research was made with the aim to obtain information about the influence of leadership and the influence of work discipline on employee motivation which affects the performance of study employees at PT Atlas Resources Tbk. South Jakarta.

The research method used is the clause associative method, for testing and measuring the effect of each variable using a statistical program that is Statistical Package for Social Science (SPSS) version 24. The subjects used are all employees of PT Atlas Resources Tbk South Jakarta as many as 125 people 
The results of the study at PT Atlas Resources Tbk South Jakarta as follows: (1) There is a positive and significant influence between the leadership variables on motivation with tcount 21.665> t table 1.979 coefficient of determination equal to $79.2 \%$. (2) There is a positive and significant influence between work discipline variables on motivation with a $T$ value of 23.948> $t$ table 1.979 coefficient of determination of $81.8 \%$. (3) There is a positive and significant influence between the variables of leadership and work discipline on employee motivation to calculate F632618> Ftable 3.07, the coefficient of determination of 84.3\%. (4) There is a positive and significant influence between the leadership variables on performance with tcount 21,368> ttable 1,979, the coefficient of determination is 78.8\%. (5) There is a positive and significant effect between work discipline variables on performance with a tcount of 29.408> t table 1.979, the coefficient of determination of 87.5\%. (6) There is a positive and significant effect between the variables of work motivation on performance with a value of 22.927> t table 1.979, the coefficient of determination of $81 \%$. Thus, each variable can significantly influence motivation which has a positive impact in improving employee performance at PT Atlas Resources Tbk South Jakarta.

Keywords: Leadership, Work Discipline, Motivation, and Performance

\section{PENDAHULUAN}

\section{A. Latar Belakang Masalah}

Dalam perkembangan teknologi saat ini dan semakin cepatnya pertumbuhan ekonomi baik dalam dunia bisnis ataupun organisasi, perusahaan harus siap dan mampu bersaing untuk dapat bertahan dalam dunia persaingan bisnis. Tentunya dibutuhkan manusia yang berkualitas dan berdaya saing untuk organisasi atau perusahaan agar dapat mempertahankan kualitas dan kinerja perusahaan.

Tidak dapat dipungkiri bahwa sumber daya manusia yang memiliki potensial dan kemapuan sangat diperlukan oleh organisasi atau perusahaan untuk mengarungi persaingan bisnis yang semakin hari semakin ketat. Karena roda perusahaan dapat berjalan sesuai tujuan yang hendak dicapai adalah dengan melalui sumber daya manusia yang mampu diandalkan dan berdaya saing.

PT.Atlas Resources Tbk adalah perusahaan pertambangan batu bara. PT. Atlas Resources Tbk memiliki visi yaitu Menjad produsen batubara terkemuka melalui jiwa kewirausahaan. Sedangkan misi dari PT. Atlas Resources Tbk yaitu 1).bMembangun organisasifyangtadaptif, 2). Memberikan imbalbhasiltterbaik bagibpemegang saham, 3).Menjalankan pola kemitraan dengan penuh integritas, 4). Meningkatkan kesejahteraan masyarakat lokal, 5). Menerapkan prinsip-prinsip bisnis yang sehat, 6). Menjadi proaktif dalam melestarikan lingkungan hidup, 7).Mengelola keanekaragaman proyek dan kelestarian sumber daya, 8).Tahan uji.

Di dalam mendukung suatu visi dan misi dan dengan melihat isi perkembangan persaingan bisnisghsaatghinightentunyaghPT.Atlas Resources Tbk harus mempunyai asset berupa sumber daya manusia yang mempunyai kualitas kinerja yang tinggi dan memiliki potensial untuk mencapai tujuan yang sudah di rencanakan sehingga tujuan tersebut dapat tercapai.

Pokok pentingnya di dalam sebuah organisasi/perusahaan adalah kepemimpinan, sebab kepemimpinan adalah simbol yang dapat membawa perusahaan menuju kepada tujuan yang hendak dicapaitr. Setiap pemimpin mempunyai cara tersendiri dalam memimpin bawahannya dan diharapkan cara memimpin tersebut selaras dengan tujuan tujuan yang sudah di tetapkan sebelumnya. 
Berdasarkan semua masalah yang sudah dibahas, sebaiknya pimpinan dapat membuat peraturan yang sesuai untuk dapat meningkatkan kedisiplinan karyawan dan tentunya dengan semua peraturan yang sudah dibuat akan dapat meningkatkan motivasi karyawan sehingga akan berdampak dan berpengaruh terhadap peningkatan kinerja karyawan. Oleh sebab itu penelitian ini dimaksudkan untuk mengetahui kepemimpinan, peningkatan kinerja, disiplin kerja dan motivasi kerja karyawan baik faktor yang menjadi penghambat ataupun faktor yang mendukung peningkatan kinerja khususnya pada PT. Atlas Resources Tbk Jakarta Selatan.

Sesuai dengan pembahasan tersebut peneliti bermaksud untuk menggali lebih dalam tentang permasalahan-permasalahan yang tejadi yang akan peneliti susun dalam bentuk penelitian dengan judul "Pengaruh Kepemimpinan dan Disiplin Kerja Terhadap Motivasi Serta Dampaknya Terhadap Kinerja Karyawan Pada PT. Atlas Resources Tbk Jakarta Selatan”.

\section{B. Perumusan Masalah}

1. Apakah kepemimpinan ada pengaruh terhadap motivasi kerja karyawan pada PT Atlas Resources Tbk Jakarta Selatan?

2. Apakah kedisiplinan kerja memberikan pengaruh terhadap motivasi kerja karyawan pada PT Atlas Resources Tbk Jakarta Selatan?

3. Apakah kepemimpinan dan disiplin kerja memberikan pengaruh terhadap motivasi kerja karyawan pada PT Atlas Resources Tbk Jakarta Selatan?

4. Apakah kepemimpinan memberikan pengaruh terhadap kinerja karyawan pada PT Atlas Resources Tbk Jakarta Selatan?

5. Apakah kedisiplinan kerja memberikan pengaruh terhadap kinerja karyawan pada PT Atlas Resources Tbk Jakarta Selatan?

6. Apakah motivasi memberikan pengaruh terhadap kinerja karyawan PT Atlas Resources Tbk Jakarta Selatan?

\section{TINJAUAN PUSTAKA}

\section{A. Pengertian Kepemimpinan}

Pemimpin adalah panutan dan setiap tindakan akan mencerminkan sikap dan perilakunya baik didalam maupun diluar organisasi. Baik buruknya sebuah organisasi akan tercermin dari cara atau bagaimana cara seorang pemimpin dalam mengayomi bawahannya. Menurut Wilson Bangun (2011:131) Pemimpin adalah proses mengarahkan dan memberikan pengaruh terhadap orang lain agar termotivasi dalam melaksanakan tugasnya untuk dapat mencapai tujuan organisasi secara diplomatis.

\section{B. Kedisiplinan}

Disiplin merupakan taat atau tidaknya seseorang terhadap peraturan yang sudah ditetapkan baik oleh perusahaan ataupun organisasi. Menurut Sutrisno (2012:86) Disiplin adalah sikap seseorang kerelaan atau kesediaan seseorang dalam mematuhi norma dan peraturan yang berlaku pada sebuah organisasi atau perusahaan. Disiplin perlu ditanamkan pada setiap diri karyawan agar mereka senantiasa terbiasa datang tepat waktu, menyelesaikan tugas dengan tepat, dan seiring berjalannya waktu maka tujuan perusahaan dapat tercapai.

\section{Motivasi}

Menurut Hasibuan (2003:92) Motivasi adalah dorongan atau kekuatan yang mendasari jiwa dan jasmaninya bergerak untuk berbuat sesuatu baik bergerak dalam tingkah laku maupun perbuatannya dengan tujuan tertentu. Sedangkan menurut M. Kadarisman (2012: 278), Motivasi adalah dorongan dan gerakan 
dalam diri seseorang untuk berperilaku maupun untuk bekerja dengan baik sesuai dengan apa yang sudah menjadi tanggungjawabnya.

\section{Kinerja}

Kinerja adalah hasil pekerjaan berupa kualitas atau jumlah yang dihasilkan oleh seseorang sesuai dengan target dan tanggung jawab yang diberikan kepadanya. Kinerja akan dicapai secara optimal apabila pemimpin dan bawahan saling bersinegi, baik dari komunikasi, kepercayaan pemimpin terhadap bawahan maupun peraturan yang dibuat harus berdasarkan kemampuan dari karyawankaryawan perusahaan tersebut. Menurut Wibowo (2011:7), kinerja adalah tingkatan pencapaian dari hasil kerja yang ditentukan oleh ukuran tertentu yang berlaku di organisasi atau perusahaan tersebut.

\section{E. Hipotesis}

1. Pengaruh Kepemimpinan (X1) terhadaptrMotivasi (Y)

Kepemimpinan (X1) berpengaruh positif dan signifikan terhadap Motivasi (Y) di PT Atlas Resources Tbk Jakarta Selatan.

2. Pengaruh Disiplin Kerja (X2) terhadap Motivasi (Y)

Disiplin Kerja (X2) berpengaruh positif dan signifikan terhadap Motivasi (Y) di PT Atlas Resources Tbk Jakarta Selatan.

3. Pengaruh Kepemimpinan (X1) dan Disiplin Kerja (X2) seara bersama-sama terhadap terhadap Motivasi (Y)

Kepemimpinan (X1) dan Disiplin Kerja (X2) berpengaruh positif dan signifikan secara bersama-sama terhadap Motivasi (Y) di PT Atlas Resources Tbk Jakarta Selatan.

4. Pengaruh Kepemimpinan (X1) terhadap terhadap Kinerja (Z)

Kepemimpinan(X1) memberi berpengaruh positif dan signifikan terhadap Kinerja (Z) di PT Atlas Resources Tbk Jakarta Selatan.

5. Pengaruh Kedisiplinan Kerja (X2) Terhadap Peningkatan Kinerja Karyawan (Z) Disiplin Kerja Karyawan (X2) memberi pengaruh positif dan signifikan terhadap peningkatan kinerja karyawan (Z) di PT.Atlas Resources Tbk Jakarta Selatan

6. Pengaruh Motivasi (Y) terhadap Kinerja (Z)

Motivasi kerja karyawan (Y) berpengaruh positif dan signifikan terhadap Kinerja (Z) di PT Atlas Resources Tbk Jakarta Selatan.

\section{METODOLOGIRFPENELITIAN}

\section{A. TempatrddanerWaktu Penelitian}

PT. Atlas Resources Tbk Jln. Kemang Raya No. 43 Jakarta Selatan 12730 adalah tempat penelitian ini dilaksanakan. Dan untuk melakukan penelitian tersebut waktu yang diperlukan penulis selama 5 (lima) bulan mulai bulan Oktober 2018 sampai dengan bulan Februari 2019.

\section{B. Metode Penelitian}

Di penelitian ini peneliti mencari pengaruh kepemimpinan, disiplin terhadap motivasi yang berdampak terhadap kinerja karyawan di PT Atlas Resources Tbk Jakarta Selatan dengan metode kuantitatif serta akan dicari besar kecilnya pengaruh kepemimpinan, disiplin kerja terhadap motivasi serta dampaknya terhadap kinerja karyawan Pada PT Atlas Resources Tbk Jakarta Selatan.

\section{Populasi dan Sampel}

Populasi di dalam penelitian ini adalah karyawan PT Atlas Resources Tbk Jln. Kemang Raya No 43 Jakarta Selatan, yang berjumlah 125 karyawan.

\section{Rancangan Analisis}


Rancangan analisis data dengan menggunakan uji validitas dan uji reliabilitasrt beserta uji asumsi klasik dan juga analisis regresi linear berganda.

\section{HASIL PENELITIAN DAN PEMBAHASAN}

\section{A. Analisis Data}

\section{Hasil Uji Validitas}

Dari hasil uji data yang dilakukan maka diperoleh nilai $r$ hitung untuk kuisioner no 1 pada variabel kepemimpinan 0,526>0,176, kedisiplinan $0,496>0,176$, motivasi $0,475>0,176$, kinerja 0,528>0,176 sehingga semua pernyataan dapat dikatakan Valid atau dipercaya.

2. Hasil Uji Reliabilitas

Hasil uji reliabilitas data yang dilakukan maka diperoleh nilai $\mathrm{r}$ ca untuk kuisioner no 1 pada variabel kepemimpinan $0,826>0,60$, kedisiplinan $0,787>0,60$, motivasi $0,781>0,60$, kinerja $0,774>0,60$ sehingga seluruh pertanyaan dapat dikatakan reliabel atau baik.

\section{Hasil Uji Regresi Linear Berganda}

\section{Tabel 4.1}

Hasil dari Uji T (Parsial ) Kepemimpinan Terhadap Motivasi

Coefficients $^{\mathbf{a}}$

\begin{tabular}{|c|c|c|c|c|c|c|}
\hline \multirow{2}{*}{ Model } & \multicolumn{2}{|c|}{$\begin{array}{c}\text { Unstandardized } \\
\text { Coefficients }\end{array}$} & $\begin{array}{c}\text { Standardized } \\
\text { Coefficient }\end{array}$ & \multirow{2}{*}{ T } & \multirow{2}{*}{ Sig. } \\
\cline { 2 - 7 } & B & $\begin{array}{c}\text { Std. } \\
\text { Error }\end{array}$ & Beta & \\
\hline \multirow{2}{*}{1} & (Constant) & 13.710 & 2.254 & & 6.106 & .000 \\
\cline { 2 - 7 } & \multirow{2}{*}{ Kepemimpinan } & .787 & .036 & .890 & 21.665 & .000 \\
\hline \multicolumn{2}{|l|}{ a. Dependent Variable: Motivasi }
\end{tabular}

Tabel 4.2

Hasil Uji T (Parsial) Disiplin Kerja Terhadap Motivasi

Coefficients $^{\mathbf{a}}$

\begin{tabular}{|l|c|c|c|c|c|c|}
\hline \multirow{2}{*}{ Model } & \multicolumn{2}{|c|}{$\begin{array}{c}\text { Unstandardized } \\
\text { Coefficients }\end{array}$} & $\begin{array}{c}\text { Standardized } \\
\text { Coefficient }\end{array}$ & \multirow{2}{*}{ Model } & \multirow{2}{*}{ Sig. } \\
\cline { 2 - 6 } & B & $\begin{array}{c}\text { Std. } \\
\text { Error }\end{array}$ & & & \\
\hline \multirow{2}{*}{1} & (Constant) & 13.738 & 2.069 & & 6.639 & .000 \\
\cline { 2 - 6 } & Disiplin Kerja & .793 & .034 & .904 & 23.498 & .000 \\
\hline \multicolumn{2}{|l|}{ a. Dependent Variable: Motivasi }
\end{tabular}

Tabel4.3

Hasil dari Uji T(Parsial) Kepemimpinan Terhadap Kinerja

\begin{tabular}{|c|c|c|c|c|c|c|}
\hline \multicolumn{7}{|c|}{ Coefficients $^{\mathbf{a}}$} \\
\hline \multirow{2}{*}{\multicolumn{2}{|c|}{ Model }} & \multicolumn{2}{|c|}{$\begin{array}{l}\text { Unstandardizedjf } \\
\text { Coefficients }\end{array}$} & \multirow[t]{2}{*}{$\begin{array}{c}\text { Standardized } \\
\text { Coefficient }\end{array}$} & \multirow{2}{*}{ Model } & \multirow{2}{*}{ Sig. } \\
\hline & & B & $\begin{array}{l}\text { Std. } \\
\text { Error }\end{array}$ & & & \\
\hline \multirow{2}{*}{1} & an(Constant) & 14.255 & 2.258 & & 6.313 & .000 \\
\hline & Kepemimpinan & .781 & .037 & .888 & 21.368 & .000 \\
\hline
\end{tabular}

a. Dependent Variable: Kinerja karyawan

\section{Tabel4.4}

Hasil dari Uji T (Parsial) Disiplin Kerja Terhadap Kinerja 
Coefficients $^{\mathbf{a}}$

\begin{tabular}{|c|c|c|c|c|c|c|}
\hline \multicolumn{2}{|c|}{ Model } & \multicolumn{2}{|c|}{$\begin{array}{c}\text { Unstandardized } \\
\text { Coefficients }\end{array}$} & $\begin{array}{c}\text { Standardized } \\
\text { Coefficient }\end{array}$ & \multirow{2}{*}{ Model } & \multirow{2}{*}{ Sig } \\
\cline { 2 - 5 } & B & $\begin{array}{c}\text { Std. } \\
\text { Error }\end{array}$ & & 7.330 & .000 \\
\hline \multirow{2}{*}{1} & (Constant) & 12.473 & 1.702 & & 29.408 & .000 \\
\cline { 2 - 5 } & Disiplin Kerja & .816 & .028 & .936 & & \\
\hline
\end{tabular}

b. Dependent Variable: Kinerja

Tabel4.5

Hasil Dari Uji T (Parsial) Disiplin Kerja Terhadap Motivasi Coefficients $^{\mathrm{a}}$

\begin{tabular}{|c|c|c|c|c|c|c|}
\hline \multicolumn{2}{|c|}{ Model } & \multicolumn{2}{|c|}{$\begin{array}{c}\text { Unstandardized } \\
\text { Coefficient }\end{array}$} & $\begin{array}{c}\text { Standardized } \\
\text { Coefficient }\end{array}$ & \multirow{2}{*}{ Model } & \multirow{2}{*}{ Sig } \\
\cline { 2 - 7 } & B & $\begin{array}{c}\text { Std. } \\
\text { Error }\end{array}$ & & \\
\hline \multirow{2}{*}{1} & (Constant) & 6.649 & 2.435 & & 2.730 & .007 \\
\cline { 2 - 6 } & Motivasi & .895 & .039 & .900 & 22.927 & .000 \\
\hline
\end{tabular}

a. Dependent Variable: Kinerja

Tabel 4.6

Uji Simultan Kepemimpinan (X1) Disiplin (X2) Terhadap Motivasi (Y)

\begin{tabular}{|c|c|c|c|c|c|c|}
\hline \multicolumn{7}{|c|}{ ANOVA $^{\text {a }}$} \\
\hline \multirow{2}{*}{ Model } & $\begin{array}{c}\text { Sum of } \\
\text { Square }\end{array}$ & Df & Mean Square & F & Sig. \\
\hline \multirow{3}{*}{1} & prRegression & 2308.799 & 2 & 1154.399 & 326.518 & $.000^{\mathrm{b}}$ \\
\cline { 2 - 8 } & Residual & 431.329 & 122 & 3.535 & & \\
\cline { 2 - 8 } & Total & 2740.128 & 124 & & & \\
\hline
\end{tabular}

a. Dependent Variable : Motivasi

b. Predictors: (Constants), Disiplin kerja, kepemimpinan.

Dalam tabel ANOVA didapat Nilai $\mathrm{F}_{\text {hitung }}$ 326,518 $>\mathrm{F}_{\text {tabel }}$ 3,07,signifikansi $0,000<0,05$ menjelaskan bahwa $\mathrm{H}_{0}$ ditolak dan $\mathrm{H}_{\mathrm{a}}$ diterima, berarti bahwa variabel dari kepemimpinan (X1) kedisiplinan kerja (X2) secara bersamasama memberikan pengaruh terhadap motivasi kerja karyawan (Y).

\section{Analisis Koefisien Determinasi}

Koefisien Determinasi Regresi Sederhana

\begin{tabular}{|c|c|c|c|c|}
\hline \multicolumn{4}{|c|}{ Variabel Kepemimpinan (X) Terhadap Motivasi (Y) } \\
\hline Model & $\mathrm{R}$ & R Square & $\begin{array}{c}\text { Adjusted R } \\
\text { Square }\end{array}$ & $\begin{array}{c}\text { Std. Error of the } \\
\text { Estimate }\end{array}$ \\
\hline
\end{tabular}




\begin{tabular}{|c|c|c|c|c|}
\hline 1 & $.890^{\mathrm{a}}$ & .792 & .791 & 2.15077 \\
\hline \multicolumn{5}{|c|}{ a. Predictors: (Constant), Kepemimpinan } \\
\hline \multicolumn{5}{|c|}{$\begin{array}{l}\text { Koefisien determinasi sebesar } 0,792 \text {. Artinya kepemimpinan memberikan } \\
\text { kontribusi terhadap motivasi sebesar } 79,2 \% \text {, sedangkan sisanya sebesan } \\
20,08 \% \text { dijelaskan dan atau dipengaruhi oleh variabel lainnya diluar } \\
\text { penelitian. }\end{array}$} \\
\hline \multicolumn{5}{|c|}{$\begin{array}{c}\text { Koefisien Determinasi Regresi Sederhana } \\
\text { Variabel Disiplin Kerja }\left(\mathbf{X}_{2}\right) \text { Terhadap Motivasi }(\mathbf{Y})\end{array}$} \\
\hline Model & $\mathrm{R}$ & R Square & $\begin{array}{l}\text { Adjusted R } \\
\text { Square }\end{array}$ & $\begin{array}{l}\text { Std. Error of the } \\
\text { Estimate }\end{array}$ \\
\hline 1 & $.904^{\mathrm{a}}$ & .818 & .816 & 2.01458 \\
\hline
\end{tabular}

a. Predictors: (Constant), Disiplin Kerja

Koefisien determinasinya 0,818. Artinya disiplin kerja Memberi kontribusi terhadap motivasi kerja karyawan sebesar $81,8 \%$, dan sisanya $18,2 \%$ di jelaskan dan atau di dipengaruhi oleh variabel lainnya diluar penelitian.

Koefisien Determinasi Regresi Sederhana Variabel Kepemimpinan ( $\left.X_{1}\right)$ Terhadap Kinerja (Z)

\begin{tabular}{|c|c|c|c|c|}
\hline Model & $\mathrm{R}$ & $\mathrm{R}$ Square & $\begin{array}{c}\text { Adjusted R } \\
\text { Square }\end{array}$ & $\begin{array}{c}\text { Std. Error of the } \\
\text { Estimate }\end{array}$ \\
\hline 1 & $.888^{\mathrm{a}}$ & .7888 & .786 & 2.16295 \\
\hline
\end{tabular}

a. Predictors: (Constant), Kepemimpinan

Hasil; dari koefisien determinasi sebesar 0,788. Artinya kepemimpinan memberikan kontribusi terhadap kinerja sebesar 78,8\%, sedangkan sisanya $21,2 \%$ di jelaskan dan atau di dipengaruhi oleh variabel lainnya diluar penelitian.

Koefisien Determinasi Regresi Sederhana

Variabel Disiplin Kerja $\left(\mathbf{X}_{2}\right)$ Terhadap Kinerja $(\mathbf{Z})$

\begin{tabular}{|c|c|c|c|c|}
\hline Model & $\mathrm{R}$ & $\mathrm{R}$ Square & $\begin{array}{c}\text { Adjusted R } \\
\text { Square }\end{array}$ & $\begin{array}{c}\text { Std. Error of the } \\
\text { Estimate }\end{array}$ \\
\hline 1 & $.936^{\mathrm{a}}$ & .875 & .874 & 1.65679 \\
\hline
\end{tabular}

a. Predictors: (Constant), Disiplin Kerja

1 Koefisien determinasi 0,875. Bahwa disiplin kerja berkiontribusi terhadap kinerja $87,5 \%$ sedangkan sisanya sebesar $12,5 \%$ di jelaskan dan atau di dipengaruhi oleh variabel lainnya diluar penelitian.

Koefisien Determinasi Regresi Sederhana

Variabel Motivasi (Y) Terhadap Kinerja (Z)

\begin{tabular}{|c|c|c|c|c|}
\hline Model & $\mathrm{R}$ & R Square & $\begin{array}{c}\text { Adjusted R } \\
\text { Square }\end{array}$ & $\begin{array}{c}\text { Std. Error of the } \\
\text { Estimate }\end{array}$ \\
\hline 1 & $.900^{\mathrm{a}}$ & .810 & .809 & 2.04460 \\
\hline
\end{tabular}

a. Predictors: (Constant), Motivasi

Hasil koefisien determinasi 0,810 . Artinya motivasi kerja memberikan kontribusi terhadap kinerja sebesar $81 \%$, sedangkan sisanya sebesar $19 \%$ dijelaskan atau dipengaruhi oleh variabel lain diluar penelitian. 


\section{Hasil Uji Koefisien Determinasi Variabel Kepemimpinan (X1) dan Disiplin Kerja (X2) Terhadap Motivasi (Y)}

\begin{tabular}{|c|c|c|c|c|}
\hline Model & $\mathrm{R}$ & R Square & $\begin{array}{c}\text { Adjusted R } \\
\text { Square }\end{array}$ & $\begin{array}{c}\text { Std. Error of the } \\
\text { Estimate }\end{array}$ \\
\hline 1 & $.918^{\mathrm{a}}$ & .843 & .840 & 1.88029 \\
\hline
\end{tabular}

a. Predictors: (Constant), Disiplin Kerja, kepemimpinan

Hasil koefisien determinasi 0,843. Bahwa kepemimpinan dan disiplin kerja karyawan berkontribusi sebesar $84,3 \%$, sedangkan sisanya sebesar $15,7 \%$ dijelaskan atau dipengaruhi oleh variabel lain diluar penelitian.

\section{KESIMPULAN}

1. Terdapatht pengaruh kepemimpinan terhadap motivasi yang di buktikan dengan :

a. Nilai thitung $21,665>t_{\text {tabel }}$ sebesar 1,979 , dan nilai signifikansi sebesar $0,000<0,05$. Dapat disimpulkan bahwa H0 ditolak dan H1 diterima, ada pengaruh positif dan signifikan antara variabel kepemimpinan terhadap variabel motivasi.

b. Koefisien determinasi sebesar 0,792. Artinya kepemimpinan berpengaruh terhadap motivasi sebesar $79,2 \%$, sisanya $20,08 \%$ dipengaruhi oleh variabel lain diluar penelitian.

2. Terdapat pengaruh disiplin kerja terhadap motivasi yang di buktikan dengan :

a. Nilai $t_{\text {hitung }} 23,498>t_{\text {tabel }}$ sebesar 1,979 , dan nilai signifikansi sebesar $0,000<0,05$. Dapat disimpulkan bahwa H0 ditolak dan H2 diterima, ada pengaruh positif dan signifikan antara variabel disiplin kerja terhadap variabel motivasi.

b. Koefisien determinasi sebesar 0,818. Artinya disiplin kerja berpengaruh terhadap motivasi sebesar $81,8 \%$, sedangkan sisanya sebesar $18,2 \%$ dijelaskan atau dipengaruhi oleh variabel lain di luar penelitian ini.

3. Terdapat pengaruh kepemimpinan dan disiplin kerja terhadap motivasi yang di buktikan dengan :

a. Nilai $F_{\text {hitung }} 326,518>$ darighF $F_{\text {tabel }} 3.07$, dan nilai signifikansinya $0,000<$ 00,05 menjelaskan bahwa H0di tolak dan H3 diterima, bahwa variaabel kepemimpinan dan kedisiplinan kerja secara bersama-sama berpengaruh positif dan pada motivasi kerja karyawan.

b. Koefisien determinasi sebesar 0,843. Artinya kepemimpinan dan kedisiplinan kerja memiliki pengaruh terhadap motivasi kerja karyawan di PT.Atlas Resources Tbk Jakarta Selatan sebesar 84,3\%, sedangkan sisanya sebesar $15,7 \%$ dijelaskan atau dipengaruhi oleh variabel lain diluar penelitian.

4. Terdapat pengaruh kepemimpinan terhadap kinerja karyawan sebagai berikut ini :

a. Nilai $\mathrm{T}_{\text {hitung }} 21,368>\mathrm{t}_{\text {tabel }}$ sebesar 1,979 , dan nilai signifikansi sebesar $0,000<0,05$. Dapat disimpulkan bahwa H0 ditolak dan H4 diterima, artinya terdapat pengaruh positif dan signifikan antara variabel kepemimpinan terhadap variabel kinerja. 
b. Koefisien determinasi sebesar 0,788. Berpengaruh sebesar 78,8\%, sedangkan sisanya $21,2 \%$ dipengaruhi oleh variabel lain diluar atau dijelaskan oleh penelitian lain.

5. Terdapat pengaruh disiplin kerja terhadap kinerja yang dibuktikan dengan berikut ini:

a. Nilai nilai $t_{\text {hitung }} 29,408>$ nilai $t_{\text {tabel }}$ sebesar 1,979 , dan nilai signifikansi sebesar $0,000<0,05$. Dapat disimpulkan bahwa H0 ditolak dan H5 diterima, artinya ada pengaruh positif antara variabel disiplin kerja terhadap variabel kinerja.

b. Koefisien determinasi sebesar 0,875. disiplin berpengaruh sebesar 87,5\%, sedangkan sisanya $12,5 \%$ dipengaruhi oleh variabel diluar penelitian.

6. Terdapat pengaruh motivasi terhadap kinerja yang dibuktikan dengan :

a. Nilai thitung $22,927>t_{\text {tabel }}$ sebesar 1,979 , dan nilai signifikansi sebesar $0,000<0,05$. Dapat disimpulkan bahwa H0 ditolak dan H6 diterima, terdapat pengaruh positif antara variabel motivasi terhadap variabel kinerja.

b. Koefisien determinasi sebesar 0,810. motivasi kerja memberikan pengaruh sebesar $81 \%$, sedangkan sisanya sebesar $19 \%$ dipengaruhi oleh variabel lain diluar penelitian.

\section{SARAN}

1. Kepemimpinan

Berdasar hasil analisa deskriptif didapat informasi bahwa variabel kepemimpinan pada PT Atlas Resources Tbk Jakarta Selatan dipersepsikan Baik (B). Hal tersebut itu dapat dilihat pada nilai rata-rata score variabel kepemimpinan sebesar 4.10 ada pada interval 3.40 - 4.19 dengan kategori Baik (B). Namun demikian ada variabel dengan kategori Baik (B) namun memiliki skor terendah yaitu pada dimensi melayani dengan indikator mempercayai, bahwa sebaiknya pemimpin memberikan kepercayaan kepada bawahannya untuk membuat terobosan-terobosan yang bersifat positif. Hal tersebut tentunya akan mendorong meningkatnya motivasi karyawan dan tentunya dengan meningkatnya motivasi karyawan, maka kinerja karyawan pun akan meningkat.

2. Disiplin Kerja

Berdasarkan hasil analisa deskriptif didapat informasi bahwa variabel disiplin kerja pada PT.Atlas Resources Tbk Jakarta Selatan dipersepsikan Tinggi (T). Hal itu dapat dilihat dari nilai score variabel disiplin kerja sebesar 4.07 ada pada interval 3.40 - 4.19 dengan kategori Tinggi (T). Namun demikian ada variabel dengan kategori Tinggi (T) namun memiliki skor terendah yaitu pada dimensi teladan pimpinan dengan indikator memberi contoh, bahwa karyawan dapat melakukan tugas dengan baik sesuai keteladanan atau contoh dari pimpinan. Tentunya dengan contoh yang baik dari seorang pemimpin akan mampu meningkatkan kedisiplinan karywan, sehingga dengan kedisiplinan karyawan yang baik akan mampu meningkatkan motivasi kerja karyawan.

3. Motivasi Karyawan

Berdasarkan hasil analisa deskriptif didapat informasi bahwa variabel motivasi pada PT Atlas Resources Tbk Jakarta Selatan dipersepsikan Tinggi (T). Hal itu dapat dilihat dari nilai rata-rata score variabel motivasi sebesar 4.15 ada pada interval 3.40 - 4.19 dengan kategori Tinggi (T). Namun demikian ada variabel dengan kategori Tinggi (T) namun memiliki skor terendah yaitu pada dimensi kebutuhan fisiologi dengan indikator fasilitas kerja, bahwa karyawan bekerja 
dalam kondisi kerja yang baik dan diberi fasilitas yang mencukupi. Tentunya dengan fasilitas kerja dan kondisi kerja yang baik yang diberikan oleh perusahaan akan dapat menciptakan kenyamanan bagi karyawan dan tentunya karyawan akan termotivasi sehingga apabila motivasi karyawan tinggi maka keinginan para karyawan serta tujuan organisasi dapat tercapai.

4. Kinerja Karyawan

Berdasarkan hasil analisa deskriptif didapat informasi bahwa variabel kinerja karyawan pada PT Atlas Resources Tbk Jakarta Selatan dipersepsikan Tinggi (T). Hal itu dapat dilihat dari nilai rata-rata score variabel kinerja sebesar 4.16 ada pada interval 3.40 - 4.19 dengan kategori Tinggi (T). Namun demikian ada variabel dengan kategori Tinggi (T) namun memiliki skor terendah yaitu pada dimensi kualitas dengan indikator memenuhi tujuan, bahwa karyawan selalu berusaha untuk menyelesaikan tugas dengan penuh rasa tanggung jawab untuk mencapai hasil yang maksimal. Tentunya perusahaan harus mampu meningkatkan tanggungmbjawabfg karyawanbv dalamcv trmelaksanakan tugasrf dantr kewajibannya dalam bekerja, hal tersebut dilakukan agar karyawan dapat melaksanakan tugas dan tanggung jawab yang dibebankan kepada mereka dengan sungguh-sungguh.

5. Begitu juga untuk peneliti selanjutnya diharapkan dapat lebih mengembangkan lagi penelitian dengan luas dengan variabel-variabel yang tidak ada dalam penelitian ini.

\section{DAFTAR PUSTAKA}

Amirullah dan Budiyono Haris. (2004). Pengantar Manajemen. Yogyakarta: Graha Ilmu.

. (2015). Pengantar Manajemen. Yogyakarta: Graha Ilmu

Bangun, Wilson. (2012). Manajemen Sumber Daya Manusia. Bandung: Erlangga.

Dessler, Gary. (2009). Manajemen Sumber Daya Manusia. Edisi Kesepuluh. Jilid

1. Jakarta : PT. Indeks

Hasibuan, Malayu. S.P. (2003). Manajemen Sumber Daya Manusia. Jakarta: PT. Bumi Aksara.

Hasibuan, Malayu. (2008). Manajemen Sumber Daya Manusia. Cetakan Kesembilan. Jakarta : PT Bumi Aksara

Kadarisman, M. (2012). Manajemen Pengembangan Sumber Daya Manusia, Edisi

Pertama, Cetakan pertama, Rajawali Press, Jakarta.

Sugiyono. (2011). Metode Penelitian Administrasi dilengkapi dengan Metode $R \& D$. Bandung : Alfabeta. . (2012). Metode Penelitian Kuantitatif Kualitatif dan R\&D. Bandung: Alfabeta.

.(2013). Statistika Untuk Penelitian.Cetakan ke 23. Bandung : Alfabeta.

Wibowo. (2011). Budaya Organisasi : Sebuah Kebutuhan Untuk Meningkatkan

Kinerja Jangka Panjang. Jakarta: Rajawali Pers.

Yuniarsih, Tjutju. (2009). Manajemen Sumber Daya Manusia Teori, Aplikasi dan

Isu Penelitian. Edisi Kedua. Bandung: Alfabeta 